\title{
Enseñar a ser médico
}

\author{
A. Marañón-Cabello
}

Participar en este curso en el que figuran tan prestigiosas personas sobre un tema tan emblemático y siempre actual como es el de enseñar a ser médico, constituye para mí un honor cuyo ofrecimiento acepté con presteza como un deber que va más allá de la mera cortesía, pues estuvo alentado por el prestigio y admiración que me ofrece la Fundación Lilly, verdadera baluarte y gran acicate para el progreso de la biomedicina.

No todas las actividades exigen de quien las practica tanta grandeza moral como la medicina; los médicos, en el empeño de sus quehaceres, inciden en lo mas preciado que tienen los seres humanos: su vida y su salud. Por tanto, convertirse en médico significa mucho más allá que terminar los estudios de medicina y los años de formación del posgrado, significa adquirir una nueva forma de vida, muy vocacional, una impronta que es característica de nuestra verdadera profesión.

Harrison, el gran clínico estadounidense, en la primera edición de su obra, definía lo que se espera del médico en palabras que, aunque reflejan el sesgo de género de aquel momento, aún suenan muy bien como principio universal. Escribió: 'No cabe mayor suerte, responsabilidad u obligación en el destino del hombre que convertirse en médico. Para atender a los que sufren debe poseer conocimientos científicos, habilidades técnicas y comprensión humana; sirviéndose de todo ello con coraje, humildad y sabiduría, prestará un servicio único a sus semejantes, a la vez que formará dentro de sí un firme carácter [...]. El médico no ha de pedir más a su destino pero tampoco ha de contentarse con menos [...]. Del médico se espera abnegación, simpatía y comprensión porque el paciente no es sólo un conjunto de síntomas, signos, funciones alteradas o emociones trastornadas; es un ser humano, temeroso y esperanzado que busca alivio y confianza'.

Al hilo de estas magníficas reflexiones de Harrison, yo diría que los médicos -y más aún en la medicina actual, necesariamente tecnificada- no debemos considerar a los pacientes como casos clínicos o enfermedades, sino como personas cuyos problemas biopsicosociales o familiares, especialmente en la medicina de atención primaria, trascienden las dolencias que les incitan a solicitar el parecer facultativo. Explicitado en otros términos: es preciso, en la medicina de nuestro tiempo, que el médico adopte la actitud de una visión integral del paciente. Y es imprescindible también la calidad ética del médico, de manera que sus actuaciones se conviertan en moralmente buenas.

Como ha escrito acertadamente uno de los grandes expertos en bioética de nuestro país, el Dr. Diego Gracia, 'los actos médicos han de cumplir siempre las condiciones básicas de corrección y bondad'.

Como ha sucedido siempre, muchos enfermos están angustiados y temerosos y no debe olvidarse que el hospital moderno es un lugar que atemoriza a la mayoría de los pacientes, por lo que sigue siendo fundamental que la primera medida terapéutica del médico consista en generar un clima de confianza y sosiego, ya que sólo cuando el paciente nota un profundo interés por él, reconoce al auténtico médico.

Sin embargo, algunos factores como el trabajo en equipo, la existencia de intermediarios y los
Catedrático de Medicina y Presidente de la Real Academia de Medicina y Cirugía de Valladolid.

E-mail realacademiava@telefonica. net 
propios avances tecnológicos han propiciado un progresivo distanciamiento entre el médico y el paciente.

Además, en la medicina actual, la práctica clínica, en un contexto de contención del gasto sanitario -necesariamente reconocible, dado que la economía de la salud es finita-, ha introducido un nuevo factor adicional de tensión sobre la relación clásica entre médico y paciente. Muchos médicos deben atender al enfermo en un tiempo escaso, sin la quietud y el sosiego necesarios. Esta medicina es la antítesis del acto médico, ya que la relación entre ambos se apoya en la confianza, el respeto y el afecto por ambas partes, condiciones que difícilmente se contemplan en estas situaciones y que generan, a menudo, insatisfacción, desconfianza, ausencia de empatía e injusto desprestigio del médico y de la profesión.

Tan sólo el buen sentido clínico y la confianza del enfermo en el médico y en la institución a la que acude aminorarán la práctica de la medicina a la defensiva y evitarán el derroche en exploraciones complementarias y el temor ante el riesgo de posibles disensiones futuras.

En otro orden de cosas, el vigoroso impulso de la biomedicina se ha fraguado en los últimos 35 o 40 años, con avances importantísimos cuyo alcance no resulta fácil vaticinar a largo plazo, pero es incuestionable que estamos a las puertas de una nueva medicina, la medicina molecular, con tecnología cada vez más fiable, investigación translacional, secuenciación completa del genoma humano, curación de muchos tumores malignos y la conveniencia de la utilización de las células madre adultas como terapia paliativa de algunos trastornos, como la enfermedad de Parkinson o la diabetes autoinmune.

Por este motivo, gente bien intencionada valora en demasía la medicina actual con el pensamiento de que 'lo cura todo o casi todo'. Sin embargo, los médicos conocemos que, por desgracia, existen numerosos procesos cuya terapia efectiva se nos escapa. A este respecto merece la pena recordar a Noah Gordon en su maravilloso libro titulado $E l$ médico, cuando en una de sus páginas el maestro dice a su joven discípulo: '[...] aunque estudiaras medicina durante más de una vida, acudirían a ti gentes cuyas enfermedades son misterios'.

Como ha escrito atinadamente Puerta, 'esta fe que muchas personas profesan por la ciencia y por las idílicas posibilidades que vienen de la medicina han propiciado lo que se conoce como medicalización de la sociedad, hasta el punto de que los individuos esperan que la medicina dé soluciones a problemas que no entraban en el ámbito clínico.

Como afirma asimismo este autor, la medicalización genera la falsa creencia de que combatiendo síntomas médicos se solucionan problemas sociales, lo que ha deparado un notable incremento del número de pacientes y nuevas formas de dependencia.

Como dejó escrito Illich, la vejez, que en diversas situaciones se consideraba un privilegio dudoso o un final patético, pero nunca una enfermedad, ha sido puesta directamente sobre las órdenes médicas.

El progreso médico ha condicionado también el exagerado uso de la tecnología y la práctica de una medicina en la que subyace la idea de que todos los procedimientos farmacológicos y técnicos deben utilizarse como una tabla de salvamento con independencia del dudoso beneficio del resultado final. Muchas veces se obvian inadecuadamente los cuidados paliativos, que podían ser más beneficiosos y apropiados en numerosas situaciones. La sociedad desea y exige en muchos casos que se utilicen siempre todos los medios al alcance de la medicina para vencer las enfermedades.

Sin embargo, la excelencia de las actuaciones médicas, como afirma Rozman, seguirá siendo la base de un buen sistema sanitario, de manera que la práctica de una adecuada historia clínica, la pericia de una exploración rigurosa y la utilización de la 'inteligencia humana' en el proceso de formulación diagnóstica no podrán ser sustituidos, sino únicamente complementados, por el ordenador o la inteligencia artificial, en especial si el médico transmite al paciente bondad y calor humano e interés por sus vertientes biopsicosociales.

El médico que realiza su actividad con estas características es no sólo excelente como profesional, sino eficiente desde el punto de vista de la gestión sanitaria. Defenderemos siempre, por tanto, una medicina tecnológicamente avanzada, pero siempre emocionalmente comprometida con los pacientes.

Interesa destacar que el progreso de la biomedicina ha deparado nuevos problemas éticos y morales; así, el incremento de la expectativa de vida $y$, por ende, de la longevidad, ha modificado el acto de la muerte, o si se prefiere, la tecnifica- 
ción hace emerger nuevas formas de morir. Hace más de 50 años, la medicina escasamente tecnificada y con escasos remedios terapéuticos condicionaba que la muerte no fuera una decisión humana que demandar al médico y, por tanto, no existían razones para planificar la muerte. Pero en el siglo actual, la medicina pública, con su tecnología, profesionales sanitarios altamente cualificados y su magnífica red hospitalaria, ha propiciado que muchos pacientes se adhieran al hospital como una tabla de salvamento y, por tanto, muchos fallecimientos se producen en su seno. Antaño sucedía que la muerte se producía en la intimidad del hogar; ahora, la muerte se ha medicalizado y ya no existen pacientes desahuciados, sino terminales.

Por ello me permito recordar que al final de la vida, en situaciones de graves procesos, de crisis o desamparo, o ante el desgarro emocional de una muerte próxima, se necesita más que nunca del calor humano y la presencia del médico, quien debe proporcionar al paciente apoyo emocional, paliar sus dolores y sufrimientos e impedir que quede aislado de su familia en el medio hospitalario, evitando prolongar de forma innecesaria la vida con técnicas artificiales y con fármacos, ya que no alargar inútilmente la vida, también engrandece la medicina.

Como ha escrito el gran oncólogo Sanz Ortiz, cuyos conceptos suscribo:

- Es necesario incorporar la muerte a la vida.

- La sedación terminal permite culminar el adiós a la vida de una forma humanizada.
- El último acto de la vida debe protagonizarlo, si es posible, la propia persona, cuyos valores, prioridades y creencias deben respetarse siempre.

- Nadie debería morir con sufrimiento y nadie debería morir solo, nunca debe faltar el calor de una mano amiga.

- Asistir a una muerte digna de un ser querido es un bien personal que deja buen recuerdo y perdura en el tiempo.

\section{Bibliografía}

1. Gracia D. Fundamentos de bioética. Madrid: Eudema; 1989.

2. Gracia D. Los cambios en la relación médico-enfermo. Med Clin (Barc) 1989: 93: 100-2.

3. Illich I. Némesis médica. La expropiación de la salud. México: Joaquín Mortiz-Planeta; 1978.

4. Marañón-Cabello A. La medicina actual: luces y sombras. Med Clin (Barc) 2004; 122: 623.

5. Ortiz-Vázquez J. Encarnizamiento terapéutico, ensañamiento diagnóstico y medicina a la defensiva. Rev Clin Esp 1995: 11: 68-76.

6. Puerta JL. Reflexiones en torno a cinco hitos de la historia de la medicina que ayudan a comprender la práctica médica actual. In: Medicina Interna. Madrid: Harcourt; 2000. Vol. 1. p. XLI-XLIX.

7. Rozman. C. Fundamentos de la práctica médica hoy y mañana. In: Medicina Interna. Madrid: Harcourt; 2000. p. 7-9. 